\title{
BMJ Open The PROblem Gambling RESearch Study (PROGRESS) research protocol: a pragmatic randomised controlled trial of psychological interventions for problem gambling
}

\author{
Shane A Thomas, ${ }^{1}$ Stephanie S Merkouris, ${ }^{1}$ Colette J Browning, ${ }^{1,2}$ \\ Harriet Radermacher, ${ }^{1}$ Susan Feldman, ${ }^{1}$ Joanne Enticott, ${ }^{1}$ Alun C Jackson ${ }^{3,4}$
}

To cite: Thomas SA, Merkouris SS, Browning CJ, et al. The PROblem Gambling RESearch Study (PROGRESS) research protocol: a pragmatic randomised controlled trial of psychological interventions for problem gambling. BMJ Open 2015;5: 000385 . doi:10.1136/bmjopen-2015009385

- Prepublication history for this paper is available online. To view these files please visit the journal online (http://dx.doi.org/10.1136/ bmjopen-2015-009385).

Received 15 July 2015 Revised 3 September 2015 Accepted 21 October 2015

CrossMark

For numbered affiliations see end of article.

Correspondence to Professor Shane A Thomas; shane.thomas@monash.edu

\section{ABSTRACT}

Introduction: International prevalence rates for problem gambling are estimated at $2.3 \%$. Problem gambling is a serious global public health concern due to adverse personal and social consequences. Previous research evaluating the effectiveness of psychological interventions for the treatment of problem gambling has been compromised by methodological limitations, including small sample sizes and the use of waitlist control groups. This article describes the study protocol for a pragmatic randomised controlled trial (RCT) evaluating the effectiveness of cognitivebehavioural therapy (CBT), behaviour therapy (BT), motivational interviewing (MI) against a non-directive supportive therapy (NDST) control, in treating problem gambling.

Methods and analysis: This study was a mixedmethods design, with a parallel group, pragmatic RCT as the primary component, and embedded qualitative studies conducted alongside. A total of 297 participants were recruited from the community in Victoria, Australia. Individuals aged 18 years and over, could communicate in English and wished to receive treatment for a gambling problem were eligible. Participants were randomly allocated in to 1 of the 4 psychological interventions: CBT, BT, MI and NDST. Repeated measures were conducted at pretreatment and post-treatment, and 6 and 12 months posttreatment. The statistical analysis will use an intentionto-treat approach. Multilevel mixed modelling will be used to examine changes in the primary outcome measures: gambling symptom severity, using the Gambling Symptom Assessment Scale, and gambling behaviours (frequency, time and expenditure). Secondary outcomes are depression, anxiety, stress and alcohol use. Individual semistructured qualitative interviews were conducted at pretreatment and posttreatment and 12 months post-treatment for a subset of participants $(n=66)$.

Ethics and dissemination: This study was approved by the Victorian Department of Justice, Monash University and the University of Melbourne Human Research Ethics Committees. Findings will be reported

\section{Strengths and limitations of this study}

- The main strength of this trial is the use of a non-directive supportive therapy as a control group, enabling the examination of the durability of therapeutic effects. This study will also significantly contribute to the field through the use of qualitative methods to gain a better understanding of the treatment process that were perceived to be effective from the participants viewpoint.

- As a pragmatic randomised controlled trial, this study is able to provide evidence on the effectiveness of these interventions in real-life settings. The use of less restrictive eligibility criteria will also improve the validity of the findings, as this sample will be representative of the problem gambling population.

- The use of several psychologists may be a limiting factor in this study design; however, therapist effects will be controlled for in the analysis.

in a government report, peer-reviewed publications and conference presentations.

Trial registration number: Current Controlled Trials ISRCTN01629698.

\section{INTRODUCTION}

Various terms have been used to describe problematic levels of gambling, including disordered gambling, pathological gambling and problem gambling. According to the Diagnostic and Statistical Manual of Mental Disorders, Fifth Edition (DSM-V), a gambling disorder is characterised by "persistent and recurrent problematic gambling behaviour leading to clinically significant impairment or distress." In the context of this study, the term problem gambling is used to 
describe a severe level of gambling, based on a continuum of gambling-related harm. ${ }^{2}$ This continuum ranges from non-problem gambling, to problem gambling, where problem gambling is characterised by difficulties in limiting money and time spent on gambling and leads to adverse consequences for the gambler, others or the community. ${ }^{23}$

A recent review of international problem gambling prevalence rates indicated that problem gambling prevalence rates range from $0.5 \%$ (Denmark and the Netherlands) to $7.6 \%$ (Hong Kong). ${ }^{4}$ In Australia, the problem gambling prevalence rate is estimated at $2.1 \%$, with state-wide surveys suggesting prevalence rates ranging from $0.7 \%$ to $2.6 \% .^{4}{ }^{5}$ The prevalence of problem gambling in Victoria is estimated at 2.4\% and, interestingly, is the only state where an increase in prevalence rates was observed in recent years. ${ }^{4}$ At problematic levels, gambling has far reaching consequences, and has been described as a global public health concern, with various personal, interpersonal and community level consequences. ${ }^{6}{ }^{7}$ Extensive research has indicated that problem gambling is associated with high levels of co-occurring psychiatric disorders, such as depression, anxiety, substance abuse and personality disorders. ${ }^{8-11}$

Treatment options for problem gambling include a range of psychological, self-help, peer support and pharmacological interventions. Psychological interventions have been the most examined, to date. One of the most common psychological treatments is cognitivebehavioural therapy (CBT), combining the cognitive and behavioural models for problem gambling. The cognitive model of problem gambling purports that gamblers have certain erroneous beliefs about gambling, which are based on false assumptions and biased information processing. ${ }^{12}$ Cognitive interventions aim to correct erroneous beliefs (eg, belief that they have control over luck), by using techniques such as cognitive restructuring to correct any cognitive distortions and biases.

Generally, the behavioural model of problem gambling claims that gambling is a learned maladaptive behaviour. Behavioural interventions use classical and operational conditioning techniques to reduce the excitement and arousal linked with gambling. ${ }^{13}$ These techniques include exposure, desensitisation and aversive techniques, problem solving training and relapse prevention. The earlier treatment studies in this field were based on the examination of behavioural techniques $^{14-16}$ and to date have been the most commonly used techniques in the treatment of problem gambling. ${ }^{13}$

Motivational interviewing (MI), originally developed for the treatment of problem drinking, ${ }^{17}$ has recently been used in the treatment of other health behaviours, including problem gambling. By helping individuals explore and resolve their ambivalence, MI uses a directive and client-centred counselling approach to facilitate behaviour change. ${ }^{18}$ There are four general principles that underlie MI, including expressing empathy, developing discrepancy between an individual's current behaviour and his or her goals, rolling with an individual's resistance to change and not arguing or opposing the resistance, and supporting self-efficacy and one's ability to succeed in change. ${ }^{19}$ Common techniques used in MI include the use of open questions, affirming an individual's strengths and freedom of choice, using reflective listening to understand an individual's frame of reference and using accurate summaries to further elicit change talk. ${ }^{18}$

Overall, reviews of the treatment evidence base support the use of psychological interventions for the treatment of problem gambling. ${ }^{20-23}$ The most recent reviews, based on randomised controlled trials (RCTs), have indicated that when compared with a control group (eg, waitlist control), CBT can be effective in the treatment of problem gambling, with growing evidence to support the use of MI interventions. ${ }^{20} 23$ These reviews have highlighted the methodological limitations in the current evidence base, which will be discussed below.

Previous RCTs in problem gambling have been limited by small sample sizes. A recent review of RCTs of psychological interventions for problem gambling found that the average sample in these studies was 89 participants, ranging from 13 to $231,{ }^{20}$ with many studies lacking the statistical power required to detect change. Further complicating this issue are the high attrition rates in this field. A review of treatment dropout in psychological interventions indicated that dropout ranged from $14 \%$ to $50 \%$ (median=26\%), with not all studies dealing with the missing data adequately. ${ }^{20}{ }^{24}$ While intention-to-treat analysis has been recommended as the least biased way to estimate the effects of an intervention, not all RCTs have used this type of analysis. ${ }^{25}{ }^{26}$ Additionally, while most RCTs report dropout rates, very few have reported the associated reasons. Understanding these reasons and investigating the time points during a study where dropout is more likely to occur will enable tailoring of treatment and research programmes to address specific risk factors for dropout and hence minimise the likelihood of dropout. ${ }^{24}$

Waitlist control groups have been used frequently in the problem gambling treatment literature and are useful in determining the short-term efficacy of a treatment; however, the long-term efficacy of treatments cannot be ascertained. ${ }^{27} \mathrm{~A}$ number of different control groups have been described and recommended in the general psychological treatment outcome literature, including the 'attention control groups', ${ }^{27}$ also referred to as 'non-specific treatment component controls'. ${ }^{28}$ This type of control condition aims to provide all participants, irrelevant of group allocation, a similar experience. ${ }^{27}$ Non-specific treatment factors that can be held constant across all groups are equated (eg, attention or amount of contact with the psychologist), while the theoretically active treatment ingredients are withheld. ${ }^{27} 28$ 
Other than allowing for long-term comparisons between the treatment and control groups, this control condition could conceivably allow researchers to assert that any differences identified cannot be attributed to differences in attention from the experimenter or psychologist, as well as, the participants outcome expectancies. ${ }^{27}$

There is an increasing number of studies that are using qualitative methods alongside RCTs of complex interventions, such as semistructured interviews, focus groups and even different forms of observation. ${ }^{29}$ Qualitative studies have rarely been used in conjunction with RCTs of problem gambling treatment. A review by Lewin et $a t^{9}$ emphasised the importance and contribution qualitative studies can make to RCTs, especially where the interventions evaluated are complicated. Qualitative studies can assist in understanding the effects of these interventions as well as the mechanisms through which change occurs. This is particularly relevant in the problem gambling field, as research has indicated how diverse and heterogeneous this population is. ${ }^{30}$

Overall, further research is required to demonstrate the relative effectiveness of different psychological interventions, as this has not yet been well examined. Furthermore, RCTs of problem gambling interventions have had various methodological limitations, which need to be addressed in future research. As such, a pragmatic RCT was designed to address these methodological limitations. This article describes the study protocol of this pragmatic RCT, entitled the PROblem Gambling RESearch Study (PROGRESS). This article includes a description of the methods of the RCT and embedded qualitative studies and the baseline characteristics of the RCT sample.

\section{Trial objectives}

The primary aim of this study was to determine the effectiveness of CBT, behaviour therapy (BT) and MI in reducing gambling behaviours and gambling symptom severity, at post-treatment, 6 and 12 months follow-up, when compared with an active control condition, nondirective supportive therapy (NDST). A secondary aim is to explore participants' experiences of treatment.

\section{METHODS}

\section{Study design}

This study was a mixed-methods design, with a parallel group, pragmatic RCT as the primary component, and embedded qualitative studies conducted alongside. Figure 1 details the flow of participants through the study, according to Consolidated Standards of Reporting Trials (CONSORT). Details relating to the RCT will be described first, followed by a separate description of the embedded qualitative studies. Ethics approval for this study was obtained from the Department of Justice Human Research Ethics Committee, Monash University Human Research Ethics Committee and the University of Melbourne Human Research Ethics Committee.

\section{Recruitment and participants}

Participants were recruited from the community in Victoria, Australia, using public advertisements in major newspapers, gambling venues and online (eg, Google advertisements and Facebook and university websites). Attempts were also made to recruit participants through Gamblers Help services. Participant recruitment occurred between January 2013 and February 2014.

Individuals were eligible to participate if they were aged 18 years and over, could communicate in the English language, lived in Victoria and wished to receive treatment for a self-identified gambling problem. Individuals were excluded if they were unable to understand and provide informed consent, were at risk of self-harm or had received treatments for their gambling problems in the past 12 months from a counsellor or therapist. People with comorbid mental health disorders were not excluded from the trial. Excluding participants based on this would have led to a sample that is unrepresentative of most treatment populations due to the high rates of comorbid mental health disorders in this population.

Individuals that were interested in participating contacted the research team via a free of charge 1800 telephone number or via a designated study email. Trained research assistants were responsible for responding to any queries via telephone or email. These research assistants were also responsible for screening potential participants for eligibility. The screening process was only conducted over the telephone.

\section{Randomisation}

To ensure equal numbers across the four interventions, participants were randomised using a permuted block design. The block sizes were randomly varied to reduce the chance of the research team recognising the assignment schedule. ${ }^{31}$ The National Health and Medical Research Council (NHMRC) Clinical Trials Unit, an external and independent unit, was responsible for generating the randomisation schedule used in this study. Randomisation occurred after the pretreatment assessment interview. A research assistant was responsible for contacting the NHMRC clinical trials unit, via telephone, to ascertain the allocated intervention and was then responsible for allocating a psychologist to each participant. This research assistant was not involved in any of the post-treatment and follow-up data collection.

\section{Sample size}

To determine an appropriate effect size, the results of a recent Cochrane review of RCTs assessing psychological interventions for problem gambling was examined, and based on expected standardised effect size ranging from $\mathrm{d}=0.50$ and $\mathrm{d}=0.84$, for financial loss from gambling and frequency of gambling, respectively, the study was powered to detect the smaller reported effect size of $\mathrm{d}=0.50 .^{20}$ Sample size calculations for this trial were 


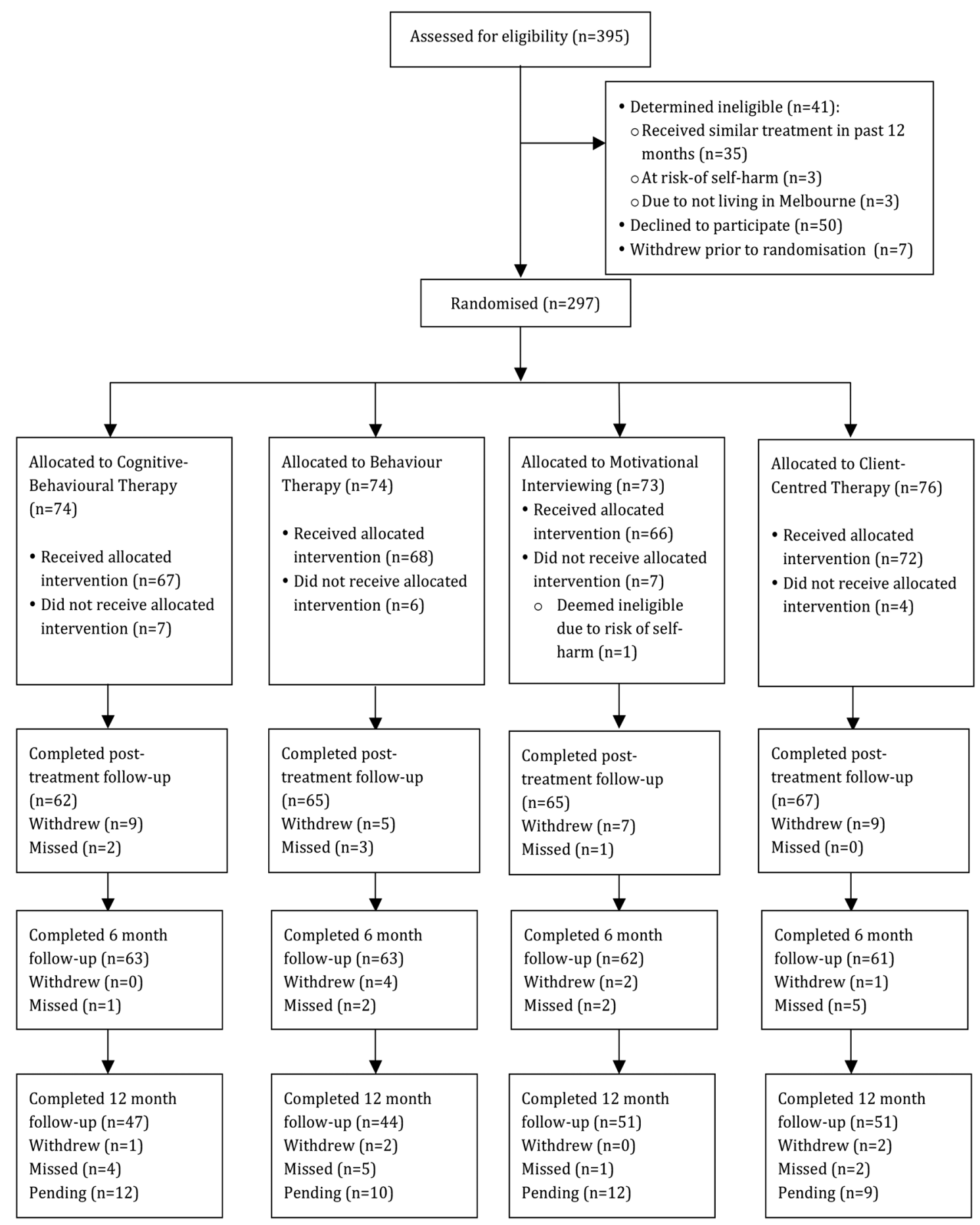

Figure 1 CONSORT diagram.

based on a rigorous power level of 0.90 , an $\alpha$ level of 0.01 , an effect size of $\mathrm{d}=0.50$ and a correlation of 0.80 between repeated measures. Overall, a sample size of $\mathrm{n}=136$ (34 per intervention) was calculated using $\mathrm{G}^{*}$ Power software and a priori repeated measures analysis of variance. However, taking in to account potentially high rates of participant dropout, a sample size of $\mathrm{n}=276$ was chosen (69 participants per intervention) to ensure sufficient statistical power.

\section{Interventions}

Participants in each intervention received up to six individual, face-to-face sessions with a registered psychologist. The sessions lasted approximately 45-60 min each and were scheduled on a weekly basis. The interventions in this RCT were each guided by a manual. All of the treatment sessions were audio-recorded for treatment fidelity purposes. A randomly selected subset of the treatment sessions were rated by two people, 
independent of the research team. A treatment fidelity checklist was developed for this purpose, with the same checklist used for all sessions.

A detailed description of the interventions is provided below. To clearly outline the differences between the interventions, see table 1 for an outline of the session structure per intervention.

\section{Cognitive-behavioural therapy}

Session 1: History taking, assessment and goal formation

The initial session involved general history taking and assessment. A treatment plan was developed based on the participant's goals for treatment and the information gathered during the initial assessment.

\section{Sessions 2-3: Gambling education and self-management techniques}

These sessions aimed to educate the participant around key areas and facts about problem gambling, as well as assist the participant in identifying key internal and external triggers that increase ones urge to gamble. Self-management techniques and strategies to deal with these triggers and urges to gamble were also addressed. These include strategies like avoiding triggers, controlling cash and thinking of alternate activities that they can do instead of gambling.

\section{Session 4-5: Identifying and challenging gambling-specific erroneous cognitions}

These sessions aimed to identify any erroneous cognitions that are commonly found in individuals with a gambling problem, such as illusions of control. Once identified, the aim was to challenge these gamblingspecific erroneous cognitions. This session also involved problem solving skills training.

\section{Session 6: Relapse prevention}

The main aim of this session was to assist the client in understanding and preventing future relapses. This session focused on alternate activities an individual could engage in to divert their attention away from gambling and help achieve a balanced lifestyle that can minimise the chances of relapsing in the future.

\section{Behavioural therapy}

Session 1: History taking, assessment and goal formation

The initial session involved general history taking and assessment. A treatment plan was developed based on the participant's goals for treatment and the information gathered during the initial assessment.

\section{Sessions 2-3: Gambling education and self-management techniques}

These sessions aimed to educate the participant around key areas and facts about problem gambling, as well as assist the participant in identifying key internal and external triggers that increase ones urge to gamble. Self-management techniques and strategies to deal with these triggers and urges to gamble were also addressed. These include strategies like avoiding triggers, controlling cash and thinking of alternate activities that they can do instead of gambling.

\section{Sessions 4-5: Imaginal exposure and reducing urges to gamble}

During these sessions, imaginal exposure were utilised to help reduce an individual's urge to gamble. This technique requires the participants to visualise real-life scenarios where they are tempted to gamble. By using relaxation techniques and discussing various alternative activities to gambling (eg, making plans with family to watch a movie), imaginal exposure aims to help the participants deal with their gambling triggers in real life.

\section{Session 6: Relapse prevention}

The main aim of this session was to assist the client in understanding and preventing future relapses. This session focused on alternate activities an individual could engage in to divert their attention away from gambling and help achieve a balanced lifestyle that can minimise the chances of relapsing in the future.

\section{Motivational interviewing \\ Sessions 1-6}

Owing to the client-centred nature of MI, the exact content of the MI sessions differ depending on various aspects, including the participant's readiness to change and their ambivalence and resistance towards change. However, underpinning each session were the basic principles of MI, including expressing empathy, rolling with resistance, supporting self-efficacy and developing discrepancy. ${ }^{19}$

The main priority for the first session was to engage with the participant and to develop a safe and positive environment. During this session, participants were offered feedback on their initial baseline assessment as a way of generating discussion. Each subsequent session began by checking in with the client and determining what they hoped to focus on in each session. Broadly, the focus of these sessions were on the participant's gambling behaviour, but this could have been narrowed down depending on the participant's main concerns and treatment goals. By the end of the six sessions, participants were assisted by their psychologist to navigate through the change process and to develop a realistic and achievable plan to help change their problematic gambling behaviour.

\section{Non-directive supportive therapy \\ Sessions 1-6}

The NDST intervention acted as a non-specific treatment control group that provided participants with characteristics common to different psychological therapies, such as attention from a therapist. ${ }^{28}$ The main characteristics of the NDST intervention were based on 
Table 1 Session structure of interventions

\begin{tabular}{|c|c|c|c|c|}
\hline Intervention & Session 1 & Session 3 & Session 4 Session 5 & Session 6 \\
\hline CBT & $\begin{array}{l}\text { History taking, assessment and goal } \\
\text { formation }\end{array}$ & $\begin{array}{l}\text { Gambling education } \\
\text { and self-management } \\
\text { techniques }\end{array}$ & $\begin{array}{l}\text { Identifying and } \\
\text { challenging } \\
\text { gambling-specific } \\
\text { erroneous cognitions }\end{array}$ & $\begin{array}{l}\text { Relapse } \\
\text { prevention }\end{array}$ \\
\hline BT & $\begin{array}{l}\text { History taking, assessment and goal } \\
\text { formation }\end{array}$ & $\begin{array}{l}\text { Gambling education } \\
\text { and self-management } \\
\text { techniques }\end{array}$ & $\begin{array}{l}\text { Imaginal exposure } \\
\text { and reducing urges to } \\
\text { gamble }\end{array}$ & $\begin{array}{l}\text { Relapse } \\
\text { prevention }\end{array}$ \\
\hline $\mathrm{MI}$ & $\begin{array}{l}\text { Engaging with the participant, explaining the } \\
\text { treatment, providing assessment feedback } \\
\text { and history taking }\end{array}$ & \multicolumn{3}{|c|}{$\begin{array}{l}\text { Check in with the participant and determine their goal for the } \\
\text { session. The exact content of each session will differ } \\
\text { depending on the participant's readiness to change and their } \\
\text { ambivalence and resistance towards change. Underpinning } \\
\text { each session will be the principles of MI, including expressing } \\
\text { empathy, rolling with resistance, supporting self-efficacy and } \\
\text { developing discrepancy }\end{array}$} \\
\hline NDST & \multicolumn{4}{|c|}{$\begin{array}{l}\text { Engaging and checking in with the participant to determine what they hope to focus on in the session. Each } \\
\text { session will be underpinned by the principles of unconditional positive regard, genuineness, empathic } \\
\text { understanding, reflective listening, staying entirely within the participant's frame of reference and avoidance o } \\
\text { volunteering leading questions, interpretations, suggestions or guidance }\end{array}$} \\
\hline
\end{tabular}

the Rogerian principles of unconditional positive regard, genuineness and empathic understanding. ${ }^{32}$

\section{Psychologist selection and training}

This study was conceptualised as a pragmatic RCT to determine the feasibility of implementation in real-life treatment settings. As such, it was decided that current practising psychologists would be utilised for the delivery of treatment in this RCT. The psychologists were required to have current registration with the Australian Health Practitioner Regulation Agency (AHPRA), have experience in delivering one of the four types of psychological interventions and experience in treating individuals with gambling problems or addictive disorders. Prior to starting work on this trial, the psychologists were required to attend a training session, where they were briefed on the study processes and how to deliver interventions for a research study. Each psychologist only delivered one type of treatment for this trial as this would assist with treatment adherence. Throughout the trial, 41 psychologists provided treatment $(\mathrm{CBT}=12$, $\mathrm{BT}=10, \mathrm{MI}=7$ and NDST $=12$ ).

\section{Treatment setting and referrals}

The treatment sessions were delivered from the psychologists' current practice. While not an exclusion criterion, participants were informed that as part of this study they would need to be able to travel to see their allocated psychologist. The trained research assistant who was responsible for the randomisation process was also responsible for allocating a psychologist to each participant and sending referral documents to the participants and psychologists. A psychologist was allocated to a participant based principally on geographical proximity.

\section{Outcome measures}

Primary outcomes for this study were changes in gambling symptom severity and gambling behaviours (frequency, time and expenditure). Secondary outcomes were changes in depression, anxiety, stress and alcohol use. See table 2 for a description of all measures, including the primary and secondary outcomes, predictor variables and general descriptive information (eg, sociodemographic and clinical history characteristics), and the time points at which they were assessed.

Sociodemographic characteristics, needed to confirm eligibility, were collected during the screening process (date of birth, gender, country of birth, language spoken at home and postcode of current residence).

All other measures were collected at pretreatment, post-treatment and at 6 and 12 months post-treatment. This included various sociodemographic characteristics (marital status, employment status, household composition, number of children, employment status, current occupation, education level, personal income and management of income) and clinical history variables (current medication and previous or current treatment for gambling, other addictions and mental health disorders).

Trained research assistants, who were blinded to the treatment allocation of participants, conducted all of the data collection interviews over the telephone. Participants were offered $\$ 50$ gift vouchers as compensation for travel costs and time at the completion of the post-treatment, and 6-month and 12-month follow-up data collection interviews.

\section{Data management}

All data and participant information are stored in password protected files, with only the research team given 
Table 2 Measures examined in the PROGRESS

\begin{tabular}{|c|c|c|c|c|c|}
\hline \multirow[b]{2}{*}{ Measures } & \multirow[b]{2}{*}{ Description } & \multicolumn{4}{|c|}{ Time point assessed } \\
\hline & & Pretreatment & Post-treatment & $\begin{array}{l}6 \text { months } \\
\text { follow-up }\end{array}$ & $\begin{array}{l}12 \text { months } \\
\text { follow-up }\end{array}$ \\
\hline \multicolumn{6}{|l|}{ Gambling-related variables } \\
\hline Gambling behaviours* $\dagger$ & $\begin{array}{l}\text { Frequency of gambling sessions, number of hours spent gambling and } \\
\text { amount of money spent gambling over a 4-week time period will be } \\
\text { assessed using self-report data }\end{array}$ & $\mathrm{x}$ & $x$ & $\mathrm{x}$ & $\mathrm{x}$ \\
\hline \multirow[t]{9}{*}{ G-SAS ${ }^{33 *} \dagger$} & $\begin{array}{l}\text { Purpose: designed to assess gambling symptom severity and change } \\
\text { during treatment }\end{array}$ & $\mathrm{x}$ & $\mathrm{x}$ & $\mathrm{x}$ & $\mathrm{x}$ \\
\hline & Number of items: 12 & & & & \\
\hline & Rating scale: five-point Likert scale with varying response options & & & & \\
\hline & Timeframe: past week & & & & \\
\hline & Subscales: urge & & & & \\
\hline & Scoring/interpretation: total scale scores range from 0 to 48 . Urge & & & & \\
\hline & $\begin{array}{l}\text { subscale scores range from } 0 \text { to } 16 \text {. The higher the score the more } \\
\text { severe the gambling symptoms }\end{array}$ & & & & \\
\hline & Psychometric properties: Cronbach's $\alpha$ of 0.87 & & & & \\
\hline & Analysis: total scale score and gambling urge subscale score & & & & \\
\hline \multirow[t]{8}{*}{ DSM-IV criteria ${ }^{34} \dagger$} & Purpose: utilised for diagnostic purposes to determine pathological & $\mathrm{x}$ & & $\mathrm{x}$ & $\mathrm{x}$ \\
\hline & gambling status & & & & \\
\hline & Number of items: 10 items & & & & \\
\hline & Rating scale: dichotomous (yes/no) & & & & \\
\hline & Timeframe: past year & & & & \\
\hline & $\begin{array}{l}\text { Scoring/interpretation: five or more positive responses indicate a } \\
\text { pathological gambling diagnosis }\end{array}$ & & & & \\
\hline & $\begin{array}{l}\text { Psychometric properties: Cronbach's } \alpha \text { of } 0.92 \text {. Has demonstrated } \\
\text { respectable specificity and sensitivity using the standard cut-off score of } 5 \text {. }\end{array}$ & & & & \\
\hline & Analysis: categorical classification of pathological gambling & & & & \\
\hline \multirow[t]{8}{*}{$P G S{ }^{2} \dagger$} & Purpose: designed to measure problem gambling & $\mathrm{x}$ & & & $\mathrm{x}$ \\
\hline & Number of items: nine items & & & & \\
\hline & $\begin{array}{l}\text { Rating scale: four-point Likert scale ranging from 'never' to 'almost } \\
\text { always' }\end{array}$ & & & & \\
\hline & Timeframe: 12 months & & & & \\
\hline & Scoring/interpretation: total scale scores range from 0 to 27 . Higher & & & & \\
\hline & $\begin{array}{l}\text { scores indicate higher problem gambling severity, with a score of } 8 \text { or } \\
\text { more indicative of gambling at problematic levels }\end{array}$ & & & & \\
\hline & Psychometric properties: Cronbach's $\alpha$ of 0.84 & & & & \\
\hline & $\begin{array}{l}\text { Analysis: total scale score, and categorical classification of problem } \\
\text { gambling }\end{array}$ & & & & \\
\hline $\begin{array}{l}\text { Family history of } \\
\text { gambling }\end{array}$ & $\begin{array}{l}\text { Single item measures to assess family history, including which family } \\
\text { member has had or previously had a gambling problem }\end{array}$ & $x$ & & & \\
\hline
\end{tabular}




\begin{tabular}{|c|c|c|c|c|c|}
\hline \multirow[b]{2}{*}{ Measures } & \multirow[b]{2}{*}{ Description } & \multicolumn{4}{|c|}{ Time point assessed } \\
\hline & & Pretreatment & Post-treatment & $\begin{array}{l}6 \text { months } \\
\text { follow-up }\end{array}$ & $\begin{array}{l}12 \text { months } \\
\text { follow-up }\end{array}$ \\
\hline Gambling debt† & $\begin{array}{l}\text { Two items were used to assess participants' self-reported } \\
\text { gambling-related debt and amount of debt }\end{array}$ & $\mathrm{x}$ & $x$ & $x$ & $x$ \\
\hline $\begin{array}{l}\text { Preferred gambling } \\
\text { activity† }\end{array}$ & Single item measure to assess preferred gambling activity type & $\mathrm{x}$ & $\mathrm{x}$ & $x$ & $\mathrm{x}$ \\
\hline $\begin{array}{l}\text { Problem gambling } \\
\text { duration }\end{array}$ & $\begin{array}{l}\text { Single item measure to assess the number of years the participant has } \\
\text { had a gambling problem }\end{array}$ & $\mathrm{x}$ & & & \\
\hline $\begin{array}{l}\text { Triggers for seeking } \\
\text { treatment }\end{array}$ & $\begin{array}{l}\text { Open-ended qualitative question exploring the reasons why participants } \\
\text { sought treatment }\end{array}$ & $\mathrm{x}$ & & & \\
\hline \multicolumn{6}{|l|}{ Psychosocial variables } \\
\hline AUDIT ${ }^{35} \dagger \ddagger$ & $\begin{array}{l}\text { Purpose: designed to identify individuals with hazardous and harmful } \\
\text { patterns of alcohol consumption } \\
\text { Number of items: } 10 \\
\text { Rating scale: five-point Likert scale } \\
\text { Timeframe: the alcohol dependence and alcohol-related problems } \\
\text { subscales have a } 12-m o n t h \text { timeframe } \\
\text { Subscales: consumption, alcohol dependence symptoms and } \\
\text { alcohol-related problems } \\
\text { Scoring/interpretation: total scale scores range from } 0 \text { to } 40 \text {. A score of } 8 \\
\text { or more indicates a strong likelihood of hazardous or harmful alcohol } \\
\text { consumption. Consumption subscale scores } 0-12 \text {; dependence subscale } \\
\text { score } 0-12 \text { and alcohol-related problems subscale score } 0-12 \\
\text { Psychometric properties: the AUDIT has displayed high internal } \\
\text { consistency and test-retest reliability ( } r=0.86) \text {. It has also displayed } \\
\text { accurate sensitivity and specificity for alcohol use disorders and good } \\
\text { discriminant validity } \\
\text { Analysis: total scale score }\end{array}$ & $\mathrm{x}$ & $\mathrm{x}$ & $x$ & $\mathrm{x}$ \\
\hline BIS- $15^{36}+$ & $\begin{array}{l}\text { Purpose: measures the construct of impulsivity } \\
\text { Number of items: } 15 \\
\text { Rating scale: four-point Likert scale, ranging from 'rarely/never' to 'almost } \\
\text { always' } \\
\text { Subscales: non-planning, motor impulsivity and attention impulsivity } \\
\text { Scoring/interpretation: total scale scores range from } 15 \text { to } 60 \text {. Each } \\
\text { subscale score ranges from } 5 \text { to } 20 \text {. Higher summed scores indicate } \\
\text { higher levels of impulsiveness } \\
\text { Psychometric properties: Cronbach's } \alpha \text { of } 0.79 \\
\text { Analysis: total scale and/or subscale scores }\end{array}$ & $\mathrm{x}$ & $\mathrm{x}$ & $\mathrm{x}$ & $\mathrm{x}$ \\
\hline Brief-COPE ${ }^{37} \dagger$ & $\begin{array}{l}\text { Purpose: measures adaptive and maladaptive coping skills } \\
\text { Number of items: } 28 \\
\text { Rating scale: four-point Likert scale, ranging from 'I haven't been doing } \\
\text { this at all' to 'l've been doing this a lot' }\end{array}$ & $\mathrm{x}$ & $\mathrm{x}$ & $\mathrm{x}$ & $\mathrm{x}$ \\
\hline
\end{tabular}


Subscales:

sychometric pror the original version of the COPE

Analysis: total subscale scores Purn-clinical populations

Rumber of items: 21

'almost always/always'

Analysis: total subscale scores

Number of items: 23 


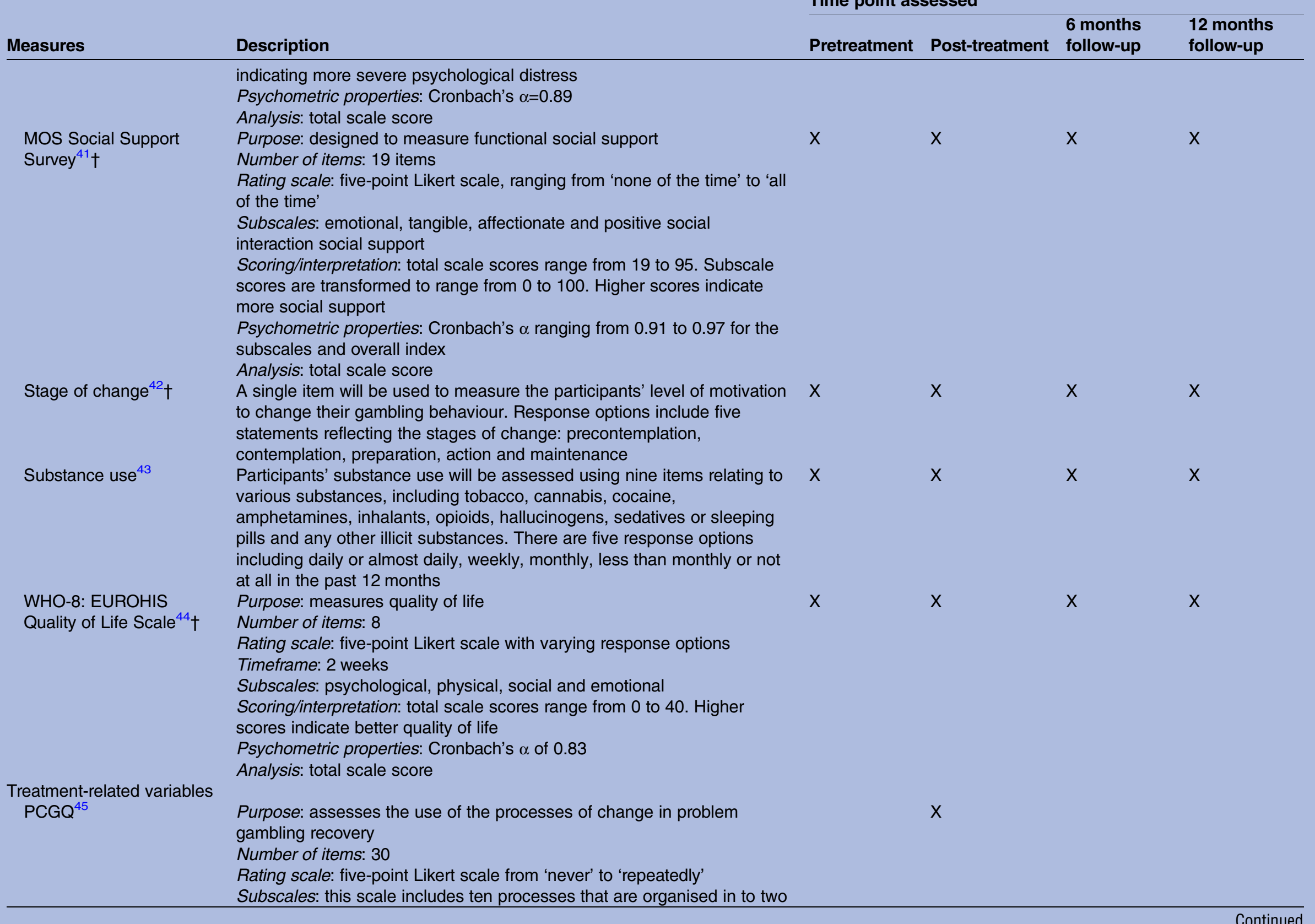




\section{Measures}

\section{Description}

Time point assessed

change processes. The cognitive-experimental processes include consciousness raising, self-re-evaluation, social liberalisation and environmental re-evaluation. The behavioural processes include helping relationships, stimulus control, counter conditioning, reinforcement management and self-liberalisation

Scoring/interpretation: each subscale score ranges from 3 to 15. Higher scores indicate higher use of processes of change

Psychometric properties: Cronbach's $\alpha$ ranging from 0.64 to 0.86 Analysis: subscale scores

Treatment goal†

One item measure assessing participant's current treatment goal. Dichotomous response option of abstinence or controlled gambling

Working Alliance Inventory ${ }^{46} \dagger$

Purpose: assesses the quality of the therapeutic alliance Number of items: 12

Rating scale: seven-point Likert scale, ranging from 'never' to 'always'

Subscales: bond, goals and tasks

Scoring/interpretation: total scale scores range from 12 to 84 with each subscale score ranging from 4 to 28 . Higher scores indicative of stronger therapeutic relationship

Psychometric properties: Cronbach's $\alpha$ of 0.93 Analysis: total scale score

*Primary outcome.

†Predictor variable.

¥Secondary outcome.

AUDIT, Alcohol Use Disorders Identification Test; BIS-15, Barratt Impulsiveness Scale-short form; COPE, Coping Orientation to Problems Experienced; DASS-21, Depression Anxiety Stress Scale 21; DSM-IV, Diagnostic and Statistical Manual of Mental Disorders, Fourth Edition; GRCS, Gambling Related Cognitions Scale; G-SAS, Gambling Symptom Assessment Scale; K6,

Kessler 6; MOS, Medical Outcomes Study; PCGQ, Process of Change Gambling Questionnaire; PGSI, Problem Gambling Severity Index. 
access. Microsoft Access was used to record any personal information required to contact participants for follow-up data collection.

The outcome-related data were entered in to the Statistical Package for the Social Sciences (SPSS) V.21, ${ }^{47}$ with no identifiable information. After entry, a random subsample of data collection interviews at each time point was checked to ensure the accuracy of the data entry. Furthermore, statistical checks were conducted during the data cleaning process. The hard copies of the data collection interviews are stored in locked filing cabinets, with only members of the research team given access.

\section{Statistical analysis}

In this pragmatic RCT, our primary analysis will be conducted using an intent-to-treat approach, and therefore include all randomised participants. Baseline characteristics of participants in the four treatment groups will be reported using frequency distributions and descriptive statistics including measures of central tendency and dispersion.

A sample of repeated measurements on the same group of participants was collected (baseline, immediately post-treatment, 6 and 12 months post-treatment), so the main analysis will be multilevel mixed modelling to examine the primary and secondary outcome measures. Random effects will account for within-participant correlation; fixed effects will be time and intervention group and the interaction of intervention and time. There are four primary outcome measures (see table 2) and two-sided tests, with an $\alpha$ level of $\mathrm{p}<0.05$ will be used to evaluate statistical significance. There are numerous secondary measures, thus an $\alpha$ level of $p<0.01$ will be used to avoid type I errors. Prespecified subgroup (covariate) analyses will be performed to explore whether comorbidities (depression, anxiety and stress) and alcohol and drug use at baseline impact the outcomes. Demographic factors such as gender and age group will also be examined.

The gambling behaviour primary outcome measures (frequency, time and expenditure) are anticipated to be positively skewed data distributions consisting of raw data bunched closer towards the zero measure and data points that more lightly scattered towards a larger number. This is anticipated based on typical samples using these measures. To improve normality of the distribution, these data will be transformed using a log (base 10) function and the transformed data used in the main analyses.

\section{Qualitative studies}

Two qualitative studies were conducted alongside the main RCT.

\section{Experiences of treatment study}

In order to obtain more detailed insight into the experiences of the participants, qualitative data were collected with a subsample of the participants who enrolled in the RCT. The aim of this qualitative study was to examine the perceptions and experiences of treatment of the participants in each of the four arms of the RCT. In particular, the barriers and enablers of change over time will be explored to further clarify why there may be heterogeneity in treatment outcomes.

During the screening process, all individuals were informed that additional, in-depth interviews with a subgroup of participants would be conducted. From those

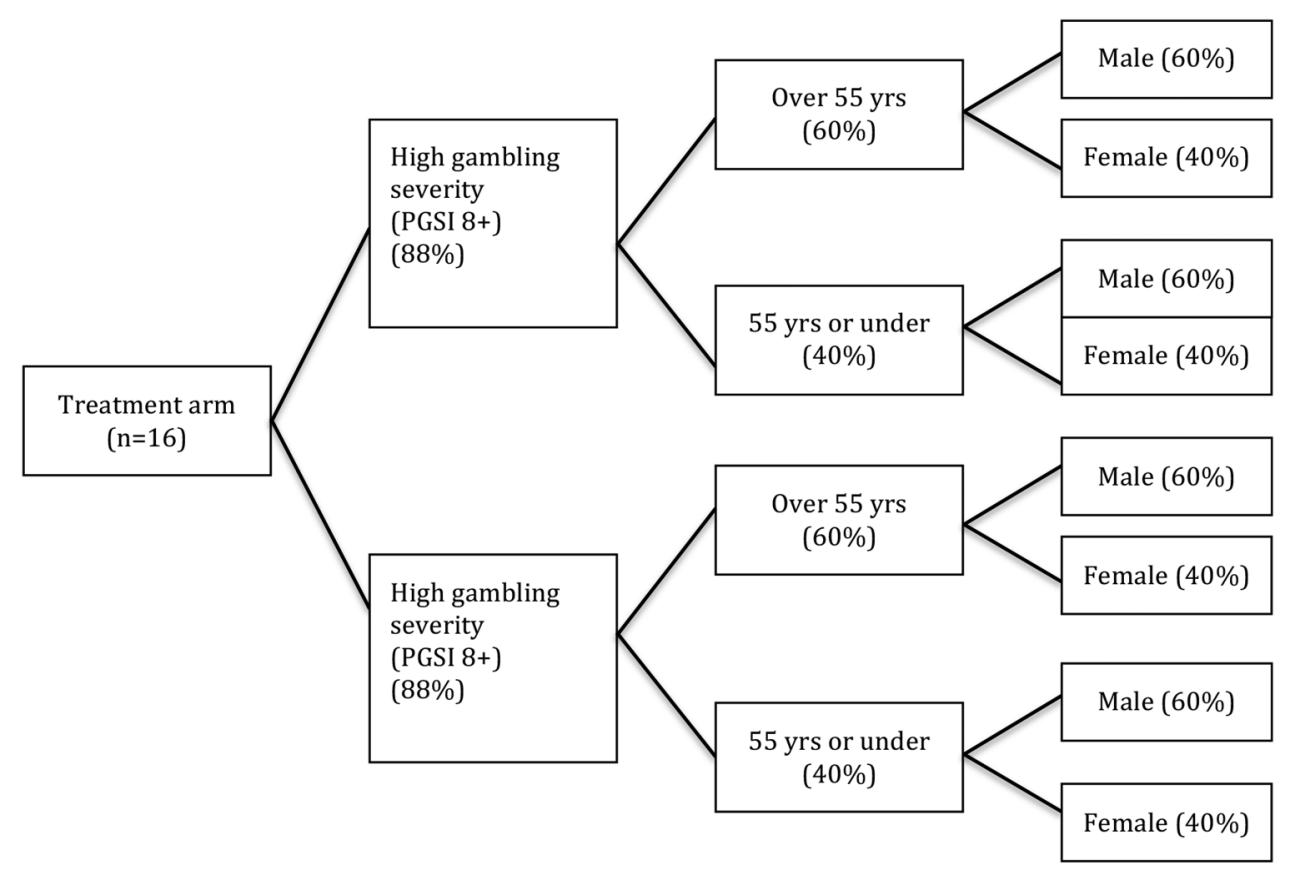

Figure 2 Sampling matrix (PGSI, Problem Gambling Severity Index). 
Table 3 Baseline characteristics

\begin{tabular}{|c|c|c|c|c|c|c|}
\hline Characteristics & CBT $(n=74)$ & BT $(n=74)$ & MI $(n=73)$ & NDST $(n=76)$ & Total $(n=297)$ & p Value \\
\hline \multicolumn{7}{|l|}{ Sociodemographic variables } \\
\hline Age (years), & $51.68(13.0)$ & $46.16(15.3)$ & $50.74(14.9)$ & $49.38(13.5)$ & $49.48(14.3)$ & 0.10 \\
\hline Male, n (\%) & $36(48.6)$ & $45(60.8)$ & $40(54.8)$ & 41 (53.9) & $162(54.5)$ & 0.53 \\
\hline Relationship, n (\%) & & & & & & 0.37 \\
\hline Married/de facto & $35(47.3)$ & $25(33.8)$ & $27(37.0)$ & $29(38.2)$ & $116(39.1)$ & \\
\hline Separated/divorced/never married/widowed & $39(52.7)$ & 49 (66.2) & $46(63.0)$ & $47(61.8)$ & $181(60.9)$ & \\
\hline Education, $\mathrm{n}(\%)$ & & & & & & 0.39 \\
\hline Tertiary education & $23(31.1)$ & $19(25.7)$ & $21(28.8)$ & $18(23.7)$ & $81(27.3)$ & \\
\hline Trade/technical certificate/diploma & $17(23.0)$ & $24(32.4)$ & $15(20.5)$ & $21(27.6)$ & 77 (25.9) & \\
\hline Completed secondary school & $11(14.9)$ & $13(17.6)$ & $20(27.4)$ & $13(17.1)$ & $57(19.2)$ & \\
\hline Completed primary school & $22(29.7)$ & $18(24.3)$ & $25(20.5)$ & $24(31.6)$ & 79 (26.6) & \\
\hline Other & $1(1.4)$ & $0(0.0)$ & $2(2.7)$ & $0(0.0)$ & $3(1.0)$ & \\
\hline Employment, n (\%) & & & & & & 0.89 \\
\hline Full-time & $30(40.5)$ & $34(45.9)$ & $27(37.0)$ & $33(43.4)$ & $124(41.8)$ & \\
\hline Part-time & $10(13.5)$ & $5(6.8)$ & $8(11.0)$ & $7(10.5)$ & $30(10.1)$ & \\
\hline Casual/self-employed & 9 (12.2) & $12(16.2)$ & $8(11.0)$ & $8(10.5)$ & $37(12.5)$ & \\
\hline Full-time student & $2(2.7)$ & $2(2.7)$ & $2(2.7)$ & $1(1.3)$ & $7(2.4)$ & \\
\hline $\begin{array}{l}\text { Not working (full-time home duties/retired/pensioner/ } \\
\text { unemployed) }\end{array}$ & $21(28.4)$ & $19(25.7)$ & $28(38.4)$ & $26(34.2)$ & $94(31.6)$ & \\
\hline Other & $2(2.7)$ & $2(2.7)$ & $0(0.0)$ & $1(1.3)$ & $5(1.7)$ & \\
\hline Income, n (\%) & & & & & & 0.44 \\
\hline Less than $\$ 25000$ & $18(24.7)$ & $20(27.0)$ & $29(39.7)$ & $20(26.3)$ & $87(29.4)$ & \\
\hline$\$ 25000-\$ 39999$ & $11(15.1)$ & $14(18.9)$ & $8(11.0)$ & $8(10.5)$ & $41(13.9)$ & \\
\hline$\$ 40000-\$ 64999$ & $17(23.3)$ & $16(21.6)$ & $9(12.3)$ & $18(23.7)$ & $60(20.3)$ & \\
\hline$\$ 65000-\$ 79999$ & $7(9.6)$ & $7(9.5)$ & $7(9.6)$ & $9(11.8)$ & $30(10.1)$ & \\
\hline$\$ 80000-\$ 129000$ & $10(13.7)$ & $14(18.9)$ & $15(20.5)$ & $15(19.7)$ & $54(18.2)$ & \\
\hline$\$ 130000$ or more & $10(13.7)$ & $3(4.1)$ & $5(6.8)$ & $6(7.9)$ & $24(8.1)$ & \\
\hline \multicolumn{7}{|l|}{ Gambling-related variables } \\
\hline Gambling symptom severity (G-SAS) & $25.82(7.013)$ & $27.48(8.17)$ & $26.14(8.93)$ & $26.14(8.04)$ & $26.39(8.05)$ & 0.61 \\
\hline Gambling frequency & $18.66(17.64)$ & $17.81(13.93)$ & $18.74(16.12)$ & $16.14(18.94)$ & $17.82(16.73)$ & 0.76 \\
\hline Hours spent gambling & $31.55(25.77)$ & $38.74(45.41)$ & $42.73(61.12)$ & $28.11(31.86)$ & $35.21(43.26)$ & 0.15 \\
\hline Gambling expenditure $(\$)$ & $3577.08(4032.66)$ & $4648.41(7420.03)$ & 4667.27 (7047.57) & $4381.75(6807.82)$ & $4320.38(6457.03)$ & 0.71 \\
\hline Pathological gamblers (DSM-IV criteria), n (\%) & $60(83.3)$ & $66(89.2)$ & $60(84.5)$ & $69(90.8)$ & $255(87.0)$ & 0.47 \\
\hline Problem gamblers (PGSI score of $8+$ ), $\mathrm{n}(\%)$ & 69 (93.2) & $65(87.8)$ & $61(84.7)$ & 70 (93.3) & $265(89.8)$ & 0.23 \\
\hline Family history of gambling problems, $\mathrm{n}(\%)$ & $28(38.4)$ & $38(51.4)$ & 35 (48.6) & $38(50.0)$ & $139(47.1)$ & 0.38 \\
\hline Years with a gambling problem & $14.54(10.58)$ & $12.69(8.77)$ & $13.62(9.79)$ & $13.22(9.27)$ & $13.51(9.59)$ & 0.69 \\
\hline EGMs as preferred mode of gambling, $n(\%)$ & $54(73.0)$ & $44(59.5)$ & $45(61.6)$ & $51(67.1)$ & $194(65.3)$ & 0.31 \\
\hline Any gambling-related debt, $n(\%)$ & $35(47.3)$ & $45(60.8)$ & $31(43.1)$ & $41(53.9)$ & $152(51.4)$ & 0.15 \\
\hline \multicolumn{7}{|l|}{ Psychological well-being variables } \\
\hline Kessler-6 & $8.95(5.00)$ & $9.45(5.77)$ & $9.55(5.56)$ & $9.67(4.91)$ & $9.40(5.30)$ & 0.85 \\
\hline
\end{tabular}




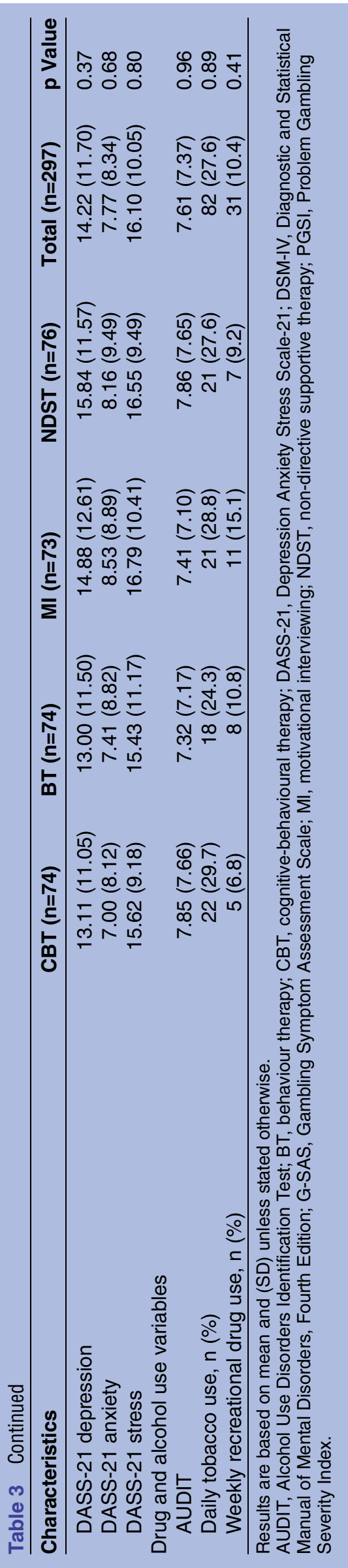

S-

ampling matrix was constructed to recruit a representative sample of the larger RCT according to treatment arm, age, sex and problem gambling severity (using the Problem Gambling Severity Index (PGSI)). All participants signed a separate consent form for these qualitative interviews. See figure 2 for the sampling matrix.

A total of 66 participants took part in the pretreatment qualitative interviews. An attempt was made to conduct post-treatment and 12-month follow-up qualitative interviews with all 66 participants. The interviews were conducted face-to-face, and took up to $60 \mathrm{~min}$.

\section{Dropout study}

In many RCTs, there is often a large attrition rate. While the attrition rate is routinely reported in such studies, it is often left unexplained. Reasons for dropping out of a study can be very diverse and can provide important information to complement and explicate the findings. As such, we aimed to identify, where possible, the reasons why participants dropout from a treatment study before it is completed. Participants who dropped out of the study were contacted as a courtesy to thank them for their participation and to investigate their reasons for dropping out. All participants who dropped out before or during the treatment period, or during the 12-month follow-up period were contacted. With participants' consent, qualitative data were collected via telephone conversations with a trained research assistant, taking approximately 5 min to complete.

Descriptive characteristics of the sample from the first qualitative study will be compared with that of the larger RCT sample. All data from both qualitative studies were audio-recorded and transcribed verbatim for entry into NVivo V.9 data management software. ${ }^{48}$ Individual transcripts will be independently read and coded by two researchers to enhance rigour. ${ }^{49}$ Systematic analysis of the qualitative data will generate a range of broad and more specific key themes related to the central aims of the study. ${ }^{50}$ Interview data will also provide in-depth case studies to examine and illustrate individual trajectories through participant's experiences of treatment and posttreatment outcomes over 1 year. ${ }^{51}$ The qualitative data will also be analysed in conjunction with the quantitative data as appropriate, with the qualitative data informing the quantitative findings and vice versa.

\section{Baseline characteristics of the participant sample}

A total of 395 individuals expressed an interest in participating in the RCT. Of these, 297 participants were randomised in to the four interventions. See figure 1 for the CONSORT diagram.

Baseline characteristics on key variables are presented in table 3 . There were no significant differences between the four interventions on any of the key sociodemographic, gambling-related or psychological variables. 


\section{DISCUSSION}

As one of the largest RCTs conducted in the field of problem gambling, this RCT will contribute to the problem gambling treatment evidence base in several ways. This RCT will build on the existing evidence base, by addressing some of the methodological limitations identified in previous RCTs.

This trial is one of the first to use a non-specific treatment component control group (ie, NDST). This will enable the examination of the long-term effects of these psychological treatments. Therefore, this RCT will be able to provide much needed evidence in to the durability of any therapeutic effects identified, as well as the patterns of change over time at a group and individual level.

One of the major challenges for this study was the potential for high dropout rates that are commonly associated with longitudinal studies, and the problem gambling population, in particular. When calculating an appropriate sample size, the commonly high attrition rates were taken in to account. Based on Melville $e t a l \mathrm{~s}^{24}$ review of dropout in psychological treatment for problem gambling, the proposed sample size allowed for the maximum $50 \%$ dropout rate, and an intention-to-treat analysis will be conducted. In addition, a parallel qualitative study will identify reasons for dropping out, further contributing important knowledge about treatment attrition.

A limitation of the current study may be that all outcome assessments were conducted over the telephone. While there is much research showing that telephone-based assessment using standardised measures is as good as face-to-face assessment, ${ }^{52-54}$ some research has shown that telephone interviews may not be as reliable as face-to-face interviews ${ }^{55}$ however, it was not feasible to conduct the large number of outcome assessment interviews face-to-face.

This trial has the potential to make a significant contribution to the problem gambling treatment field. Through the use of quantitative and qualitative methods, we aim to gain a better understanding, not only of the empirical effectiveness of the treatments, but also the components of the treatment process that participants perceive to be effective. The findings of this trial may have implications for the way current problem gambling treatment services are provided.

\author{
Author affiliations \\ ${ }^{1}$ Primary Care Research Unit, School of Primary Health Care, Monash \\ University, Notting Hill, Victoria, Australia \\ ${ }^{2}$ RDNS Institute, St Kilda, Victoria, Australia \\ ${ }^{3}$ Melbourne Graduate School of Education, University of Melbourne, Carlton, \\ Victoria, Australia \\ ${ }^{4}$ Heart Research Centre, North Melbourne, Victoria, Australia
}

Acknowledgements The authors would like to acknowledge the work of all the research assistants who assisted throughout this trial.

Contributors SAT led the conception and design of the study with contributions from ACJ, CJB, SSM, HR, SF and JE. SSM coordinated the daily running of the project. HR and SF led the qualitative data collection. JE and SSM led the statistical analysis of the baseline data. All authors will participate in the analysis and interpretation of the trial data. SSM led the drafting of the manuscript. All authors reviewed and approved the final manuscript.

Funding This study was originally funded by the Department of Justice. Management of this study was transferred on 1 July 2012 to the Victorian Responsible Gambling Foundation.

Disclaimer The opinions, findings and proposals contained in this report represent the views of the author/s and do not necessarily represent the attitudes or opinions of the Victorian Responsible Gambling Foundation or the State of Victoria. No warranty is given as to the accuracy of the information. The Victorian Responsible Gambling Foundation specifically excludes any liability for any error or inaccuracy in, or omissions from, this document and any loss or damage that you or any other person may suffer.

Competing interests None declared.

Ethics approval Victorian Department of Justice Human Research Ethics Committee, Monash University Human Research Ethics Committee and the University of Melbourne Human Research Ethics Committee.

Provenance and peer review Not commissioned; externally peer reviewed.

Open Access This is an Open Access article distributed in accordance with the Creative Commons Attribution Non Commercial (CC BY-NC 4.0) license, which permits others to distribute, remix, adapt, build upon this work noncommercially, and license their derivative works on different terms, provided the original work is properly cited and the use is non-commercial. See: http:// creativecommons.org/licenses/by-nc/4.0/

\section{REFERENCES}

1. American Psychiatric Association (APA). Diagnostic and Statistical Manual of Mental Disorders. 5th edn. Arlington, VA: American Psychiatric Publishing, 2013.

2. Ferris J, Wynne H. The Canadian Problem Gambling Index. Ottawa: Canadian Centre on Substance Abuse, 2001.

3. Neal P, Delfabbro P, O'Neil M. Problem gambling and harm: towards a national definition. Melbourne: Gambling Research Australia, 2005

4. Williams RJ, Volberg RA, Stevens RMG. The population prevalence of problem gambling: methodological influences, standardized rates, jurisdictional differences, and worldwide trends: report prepared for the Ontario Problem Gambling Research Centre and the Ontario Ministry of Health and Long Term Care, 2012. http://hdl.handle.net/ 10133/3068

5. Productivity Commission 1999. Australia's gambling industries Report No. 10. Canberra: AusInfo.

6. Shaffer $\mathrm{H}$, Korn D. Gambling and related mental disorders: a public health analysis. Annu Rev Public Health 2002;23:171-212.

7. Delfabbro P. A review of Australian gambling research. Gambling Research Australia, 2008.

8. Lorains F, Cowlishaw S, Thomas S. Prevalence of comorbid disorders in problem and pathological gambling: systematic review and meta-analysis of population surveys. Addiction 2011;106:490-8.

9. Dowling NA, Cowlishaw S, Jackson A, et al. Prevalence of psychiatric co-morbidity in treatment-seeking problem gamblers: a systematic review and meta-analysis. Aust N Z J Psychiatry 2015;49:519-39.

10. Dowling NA, Cowlishaw S, Jackson AC, et al. The prevalence of comorbid personality disorders in treatment-seeking problem gamblers: a systematic review and meta-analysis. J Pers Disord 2014;23:1-20.

11. Cowlishaw S, Merkouris S, Chapman A, et al. Pathological and problem gambling in substance use treatment: a systematic review and meta-analysis. J Subst Abuse Treat 2014;46:98-105.

12. Toneatto T. Cognitive psychopathology of problem gambling. Subst Use Misuse 1999;34:1593-604.

13. Dowling $\mathrm{N}$, Jackson A, Thomas S. Behavioral interventions in the treatment of pathological gambling: a review of activity scheduling and desensitization. Int J Behav Consult Ther 2008;4:172-87.

14. McConaghy N, Armstrong MS, Blaszczynski A, et al. Controlled comparison of aversive therapy and imaginal desensitization in compulsive gambling. Br J Psychiatry 1983;142:366-72.

15. McConaghy N, Armstrong MS, Blaszczynski A, et al. Behavior completion versus stimulus control in compulsive gambling. Behav Modif 1988;12:371-84.

16. McConaghy N, Blaszczynski A, Frankova A. Comparison of imaginal desensitization with other behavioral treatments of pathological gambling: a two- to nine-year follow-up. $\mathrm{Br} J$ Psychiatry 1991;159:390-3. 
17. Miller W. Motivational interviewing with problem drinkers. Behav Psychother 1983;11:147-72.

18. Rollnick S, Miller W. What is motivational interviewing? Behav Cogn Psychother 1995;23:325-34.

19. Miller W, Rollnick S. Motivational interviewing: preparing for change. 2nd edn. New York: Guilford Press, 2002.

20. Cowlishaw S, Merkouris S, Dowling N, et al. Psychological therapies for pathological and problem gambling. Cochrane Database Syst Rev 2012(11):CD008937.

21. Pallesen S, Mitsem M, Kvale G, et al. Outcome of psychological treatments of pathological gambling. Addiction 2005;100:1412-22.

22. Toneatto $\mathrm{T}$, Ladouceur R. Treatment of pathological gambling: a critical review of the literature. Psychol Addict Behav 2003;17:284-92.

23. Problem Gambling Research and Treatment Centre (PGRTC). Guideline for screening, assessment and treatment in problem gambling. Clayton: Monash University, 2011.

24. Melville K, Casey L, Kavanagh D. Psychological treatment dropout among pathological gamblers. Clin Psychol Rev 2007;27:944-58.

25. Higgins J, Deeks J, Altman D. Special topics in statistics. In: Higgins J, Green S, eds. Cochrane handbook for systematic reviews of interventions. Chichester, UK: John Wiley \& Sons, 2008.

26. Newell D. Intention-to-treat analysis: implications for quantitative and qualitative research. Int J Epidemiol 1992;21:837-41.

27. Spokas M, Rodebaugh T, Heimberg R. Treatment outcome research. In: McKay D, ed. Handbook of research methods in abnormal and clinical psychology. Los Angeles: Sage Publications, 2007:513-30.

28. Mohr D, Spring B, Freedland K, et al. The selection and design of control conditions for randomized controlled trials of psychological interventions. Psychother Psychosom 2009;78:275-84.

29. Lewin S, Glenton C, Oxman AD. Use of qualitative methods alongside randomised controlled trials of complex healthcare interventions: methodological study. BMJ 2009;339:b3496.

30. Blaszczynski A, Nower L. A pathways model of problem and pathological gambling. Addiction 2002;97:487-99.

31. Schulz K, Grimes D. Generation of allocation sequences in randomised trials: chance, not choice. Lancet 2002;359:515-19.

32. Rogers $\mathrm{C}$. The necessary and sufficient conditions of therapeutic personality change. J Consul Psychol 1957;21:95-103.

33. Kim S, Grant J, Potenza M, et al. The Gambling Symptom Assessment Scale (G-SAS): a reliability and validity study. Psychiatry Res 2009;166:76-84.

34. Stinchfield R, Govoni R, Frisch G. DSM-IV diagnostic criteria for pathological gambling: reliability, validity, and classification accuracy. Am J Addict 2005;14:73-82.

35. Babor T, Higgins-Biddle J, Saunders J, et al. AUDIT: the Alcohol Use Disorders Identification Test: guidelines for use in primary care. 2nd edn. World Health Organization, 2001.
36. Spinella M. Normative data and a short form of the Barratt Impulsiveness Scale. Int J Neurosci 2007;117:359-68.

37. Carver C. You want to measure coping but your protocol's too long: consider the brief COPE. Int J Behav Med 1997:4:92-100.

38. Lovibond S, Lovibond P. Manual for the depression anxiety stress scales. 2nd edn. Sydney, Australia: Psychology Foundation of Australia, 1995

39. Raylu N, Oei T. The Gambling Related Cognitions Scale (GRCS): development, confirmatory factor validation and psychometric properties. Addiction 2004;99:757-69.

40. Kessler R, Andrews G, Colpe L, et al. Short screening scales to monitor population prevalences and trends in non-specific psychological distress. Psychol Med 2002;32:959-76.

41. Sherbourne C, Stewart A. The MOS Social Support Survey. Soc Sci Med 1991;32:705-14

42. Stinchfield R, Winters K, Dittel C. Evaluation of state-supported pathological gambling treatment in Minnesota: compulsive/problem gambling services program. Minnesota Department of Human Services, 2008.

43. Allen Consulting Group, Problem Gambling Research and Treatment Centre, Social Research Centre. Social and economic impact study of gambling in Tasmania. Melbourne: Allen Consulting Group, 2011.

44. Power M. Development of a common instrument for quality of life. In: Nosikov A, Gudex C, eds. EUROHIS: developing common instruments for health surveys. Amsterdam: IOS Press, 2003:145-63.

45. Hodgins D. Processes of changing gambling behavior. Addict Behav 2001;26:121-8.

46. Horvath A, Greenberg L. Development and validation of the working alliance inventory. J Couns Psychol 1989;36:223-33.

47. IBM SPSS Statistics for Windows, Version 21.0 [program]. Armonk, NY: IBM Corp., Released 2012.

48. NVivo qualitative data analysis software [program]. 9 version, 2010.

49. Braun V, Clarke V. Using thematic analysis in psychology. Qual Res Psychol 2006:3:77-101.

50. Lincoln Y, Guba E. Naturalistic inquiry. Beverly Hills, CA: Sage, 1985.

51. Henderson $\mathrm{S}$, Holland J, McGrellis S, et al. Storying qualitative longitudinal research: sequence, voice and motif. Qual Res 2012;12:16-34.

52. Crooks VC, Clark L, Petitti DB, et al. Validation of multistage telephone-based identification of cognitive impairment and dementia. BMC Neurol 2005;5:8-15.

53. Gatz M, Reynolds CA, Nikolic J, et al. An empirical test of telephone screening to identify potential dementia cases. Int Psychogeriatr 1995;3:429-38.

54. Zhou J, Zhang X, Mundt JC, et al. A comparison of three dementia screening instruments administered by telephone in China. Dementia 2004;3:69-81.

55. Block ES, Erskine L. Interviewing by telephone: specific considerations, opportunities and challenges. Int $J$ Qual Methods 2012;11:428-45. 